\title{
Optimization of Subsidy Policy for New Energy Automobile Industry in China Based on an Integrated Fuzzy-AHP-TOPSIS Methodology
}

\author{
Xiaojia Wang $\mathbb{D}^{1,2}$ Yiming Song, ${ }^{1}$ Xuan Zhang, ${ }^{1}$ and Hui Liu ${ }^{3}$ \\ ${ }^{1}$ School of Management, Hefei University of Technology, Hefei, China \\ ${ }^{2}$ Key Laboratory of Process Optimization and Intelligent Decision, Ministry of Education, Hefei, China \\ ${ }^{3}$ New Energy Automobile Research Institute, Jianghuai Automobile Co., Ltd. (JAC), Hefei, China
}

Correspondence should be addressed to Xiaojia Wang; xjwang@hfut.edu.cn

Received 3 June 2019; Revised 19 August 2019; Accepted 9 September 2019; Published 20 November 2019

Academic Editor: Anna M. Gil-Lafuente

Copyright ( 2019 Xiaojia Wang et al. This is an open access article distributed under the Creative Commons Attribution License, which permits unrestricted use, distribution, and reproduction in any medium, provided the original work is properly cited.

With the continuous tension of the international energy supply and the increasing appeal of the global environmental protection, the development of the new energy vehicle industry has attracted international attention. In order to support the development of new energy automobile production, China has frequently issued support policies. However, the problem of subsidy fraud has been exposed. Therefore, in order to help the healthy development of China's new energy automobile industry and reduce the risk of subsidy fraud, this paper investigates 15 representative new energy auto enterprises in China and independently evaluates their performance from three aspects. We first use triangular fuzzy numbers (TFNs) to simulate an uncertain decision environment and more closely reflect the decision maker's thinking model; we then propose an analytic hierarchy process (AHP)-technique for order preference by similarity to an ideal solution (TOPSIS) method based on fuzzy data to rank 15 enterprises. Finally, according to the performance of enterprises, we propose differentiated subsidy policy recommendations. The model proposed in this paper takes into account the uncertainty of subjective evaluation so as to increase the credibility of the results. At the same time, the model can also be applied in other industries.

\section{Introduction}

The transport sector has always been one of the major contributors to increasing greenhouse gas emissions. Reports from the International Energy Agency (IEA) show that the transport's share of global greenhouse gas emissions is 23\%. Emissions increased by $2.5 \%$ annually between 2010 and 2015 (IEA, 2017). Reducing carbon emissions from transport sector plays an important role in alleviating serious environmental problems. New energy vehicle (NEV) is an innovative way of energy saving. It is recognized as one of the most promising means to reduce carbon emissions in the transportation industry. Therefore, from the perspective of sustainable development and environmental protection, it is imminent to support and promote the development of new energy vehicles $[1,2]$.

New energy vehicles refer to vehicles that use unconventional vehicle fuels as a power source, integrated advanced technologies in power control and driving, and have advanced technology, new technologies, and new structures. It includes pure electric vehicles (PEVs) [3], fuel cell electric vehicles (FCEVs), and plug-in hybrid electric vehicles (PHEVs) [4].

In recent years, China's new energy automobile industry continues to develop and has become the world's largest producer. As shown in Figure 1, from 2011 to 2017, the production and sales of new energy vehicles continued to grow. In particular, in 2015, when new energy vehicle production and sales amounted to 379,000 and 331,092 , the year-on-year growth reached 4.8 times and 4.4 times, respectively. As shown, the annual sales of the NEV increased by $204 \%$ from 2009 to 2017 . At the same time, sales volume was 777 thousand and output was 794 thousand in 2017, ranking first in the world (for more information, see the China Association of Automobile Manufacturers. Available online: http://www.caam.org.cn/). 


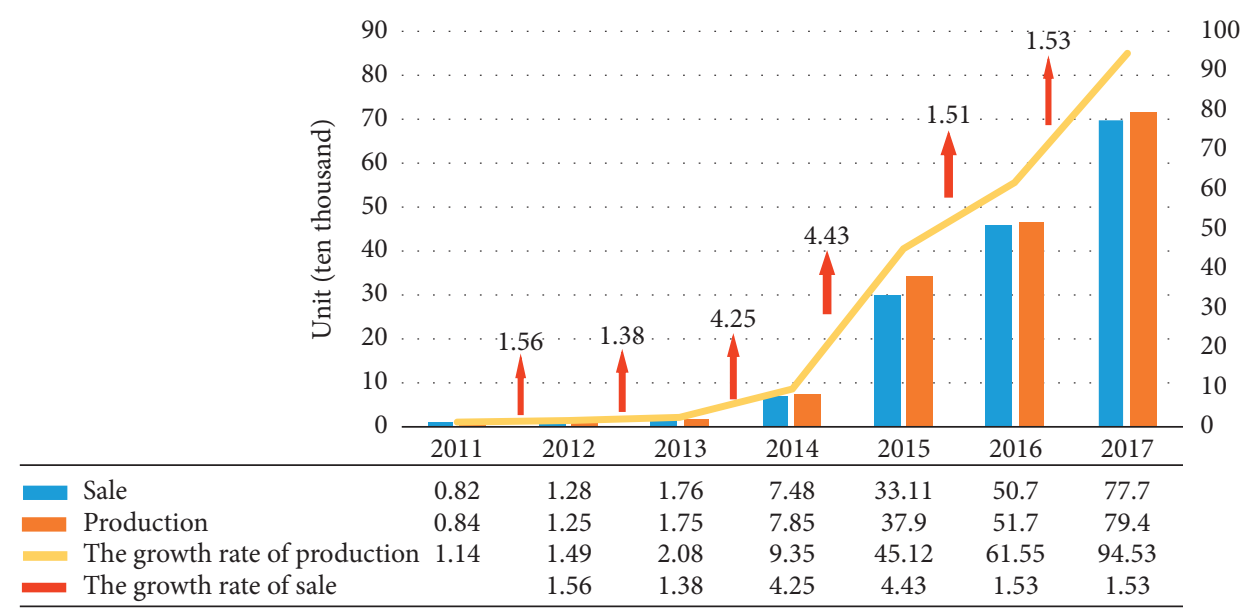

FIgURE 1: Situation of production and sale of new energy vehicles from 2011 to 2017.

In fact, it is not as simple as it seems that China's new energy auto industry has achieved such an achievement. During the development of the industry, it will face many major challenges. Therefore, China has introduced a large number of policies to support the development of the industry. Among them, the subsidy policy is the most powerful, which has greatly promoted the development of new energy vehicle industry. However, the subsidy policy makes some enterprises driven by interests to violate the relevant laws and regulations cheating for financial subsidies. For example, the case of subsidy fraud and supplement broke out in 2016. According to the disclosure of the "Securities Daily," four ministries and commissions, such as the Ministry of finance, have found that the total number of vehicles suspected of cheating and complying with illegal complements in the process of verification has reached 76374, involving a total subsidy of 9 billion 270 million yuan. By the end of 2015, China's new energy vehicles totaled 497 thousand vehicles. In order to promote the popularization and application of new energy vehicles, the central finance issued a total subsidy of 33 billion 435 million yuan from 2009 to the end of 2015. A simple calculation shows that the total number of vehicles involved in fraud accounts for $15.4 \%$ of the total output. The amount of fraud accounts for $27.7 \%$ of the total amount of central government subsidies. This phenomenon has seriously jeopardized the development of new energy vehicle industry. It not only infringed on the national financial interests and order, but also violated the legitimate rights and interests of the relevant enterprises and also caused serious harm to the society. This is likely to drive the development of new energy automotive industry to the opposite direction, thereby impeding the technological innovation and application of new energy vehicles.

The problem of new energy vehicle subsidy fraud is due to inadequate supervision by relevant departments and low entry threshold of enterprises and products. At the same time, it is worth noting that the biggest driving force of enterprises is not to create the type of cars that users want to buy through technical research. These companies will also resort to subsidy standards, realizing virtual or real sales as a means to seek the funds of taxpayers. Therefore, this paper also puts forward a subsidy policy suggestion according to the result of enterprise evaluation. This policy aims to stimulate competition among enterprises, speed up technological innovation, and promote the healthy development of the new energy vehicle industry.

In view of the above problems, this paper uses the FuzzyAHP-TOPSIS method to evaluate the new energy automobile enterprises in China and then analyzes the results and provides suggestions. First, we analyze the influencing factors of new energy automobile enterprises from three aspects and establish the index system according to the related research and expert advice. In addition, to make the data more practical, we use the triangular fuzzy number (TFN) to manage the expert ratings. Then, the Fuzzy-AHP method is used to determine the weight of each index. Furthermore, the total score of enterprises under the 11 indicators is obtained through the Fuzzy-TOPSIS method, thus reflecting the comprehensive strength of enterprises. Finally, we analyze the ranking of the enterprises and provide a differential subsidy policy on the basis of the original policy to promote the development of the new energy automobile industry and provide suggestions for the reduction of the phenomenon of subsidy fraud.

Our main contribution is to apply the Fuzzy-AHPTOPSIS model to the field of new energy vehicles and to use the TFN to create uncertain environment, which makes the subjective evaluation method more reliable. At the same time, this paper analyses the evaluation results and puts forward some suggestions to solve the problem of subsidy fraud for new energy vehicles, so as to promote the healthy development of new energy vehicles in China.

This study organizes the remaining structure as follows. In Section 2, we will review the literature. Section 3 analyses the influencing factors and establishes the index system. In Section 4, we build a Fuzzy-AHP-TOPSIS model to evaluate the performance of enterprises and provide a subsidy policy recommendation. Section 5 concludes this research. 


\section{Literature Review}

2.1. Fuzzy Numbers. The concept of fuzzy number was first proposed by Zadeh [5] and was widely applied and improved by scholars. Fuzziness is that the decision maker is not clear enough to judge things and cannot express them with definite values, including a large number of uncertain elements. In real life, similar fuzzy concepts are everywhere, for example, judging a person's quality and the full dissatisfaction of the quality of life. These problems cannot be simply measured with good and bad, each person has its own evaluation standard, and there is no absolute answer. This kind of phenomenon is a fuzzy phenomenon.

The concept of triangular fuzzy numbers was put forward by Van Laarhoven and Pedrycz [6] and combined with the logarithmic least squares method. Triangular fuzzy numbers represent the uncertainty information by the principle of geometric triangle and give a possible range of information value to be described.

2.2. Fuzzy AHP. The AHP approach was proposed by Saaty. The approach is known for its rigorousness in analyzing relative strength of preferences, qualitative judgments, and contradictory opinions of decision makers. It is a mathematical method based on a pairwise comparison matrix. The most important advantage of AHP is that it can change a complex problem with hierarchical structure, which includes objectives, standards, substandards, and alternatives. The main functions of this method include creating a hierarchical structure that is not restricted by the number of layers, establishing preferences through simple pairwise comparison, and checking logical compatibility through measurements [7].

Despite its wide scope of application, the conventional AHP approach may not fully reflect human thinking. One reason is that decision makers usually feel more confident to express their judgments in intervals rather than in single numerical values. Thus, fuzzy AHP and its extensions have been developed to solve alternative selection and justification problems. Van Laarhoven and Pedrycz were the first researchers to introduce the application of fuzzy logic principle to AHP. They propose a fuzzy logarithmic least square method to obtain triangular fuzzy weights from triangular fuzzy pairwise comparison matrices. Chang [8] introduces the use of triangular fuzzy numbers for the pairwise comparison scale of FAHP. He suggests an extent analysis method, which derives crisp weights of alternative from fuzzy pairwise comparison matrices. Because of its simplicity, Chang's extent analysis method has been used by researchers in many areas until Wang et al. [9] demonstrate that the priority vectors determined by the extent analysis method in FAHP problems did not represent the relative importance of decision criteria or alternatives and may have led to a wrong decision. Mikhailov [10] proposes two methods to derive crisp priorities from fuzzy pairwise comparison judgments based on fuzzy preference programming, but he does not consider nonlinearity of the fuzzy reciprocal numbers. Rezaei et al. [11] suggests an improvement of fuzzy preference programming that can correct this drawback. FAHP has proved to be a very useful method and has been applied in various fields.

2.3. Fuzzy TOPSIS. TOPSIS (technique for order performance by similarity to ideal solution) was first developed by Hwang and Yoon [12]. According to this technique, the best alternative would be the one that is nearest to the positive ideal solution and farthest from the negative ideal solution [13]. The positive ideal solution is a solution that maximizes the benefit criteria and minimizes the cost criteria, whereas the negative ideal solution maximizes the cost criteria and minimizes the benefit criteria [14]. In short, the positive ideal solution is composed of all best values attainable from the criteria, whereas the negative ideal solution consists of all worst values attainable from the criteria [9]. There have been lots of studies in the literature using TOPSIS for the solution of MCDM problems.

When handling inexact and vague information, particularly modeling human judgments, it is more realistic and intuitive to use linguistic assessments instead of numerical evaluations. Thus, in many previous studies, the TOPSIS method was used in conjunction with fuzzy logic. Numerous fuzzy TOPSIS methods and applications have been developed since the 1990s, e.g., for supplier selection $[15,16]$, finance $[17,18]$, power industry $[19,20]$, and negotiation problems [21].

Although the Fuzzy-AHP-TOPSIS model has been widely used in various fields, the model is rarely used in the field of new energy vehicles. Therefore, the purpose of this paper is to use this model to analyze new energy auto companies and propose subsidy policies that can promote the development of new energy auto industry. Figure 2 shows the framework of this paper.

\section{Data Collection and Evaluation Indicators System}

3.1. Data Collection. The data in this paper mainly come from the "Recommended Vehicle Catalog for New Energy Vehicles Popularization and Application" released by the Ministry of Industry and Information Technology (MIIT) in 2017 (for more information, see http://123.127.164.29:18082/ CVT/Jsp/zjgl/nerds/201711.html). Then, 15 representative enterprises were selected from the catalog by the expert group. At the same time, it is necessary to explain that our team is composed of 15 experts with rich experience in new energy vehicles. The panel included experts from Chery Automobile (3 people), JAC (5 people), China Association of Automobile Manufacturers (5 people), and Hefei University of Technology Automotive Institute ( 2 people). The data used to support the findings of this study are included within the article. 


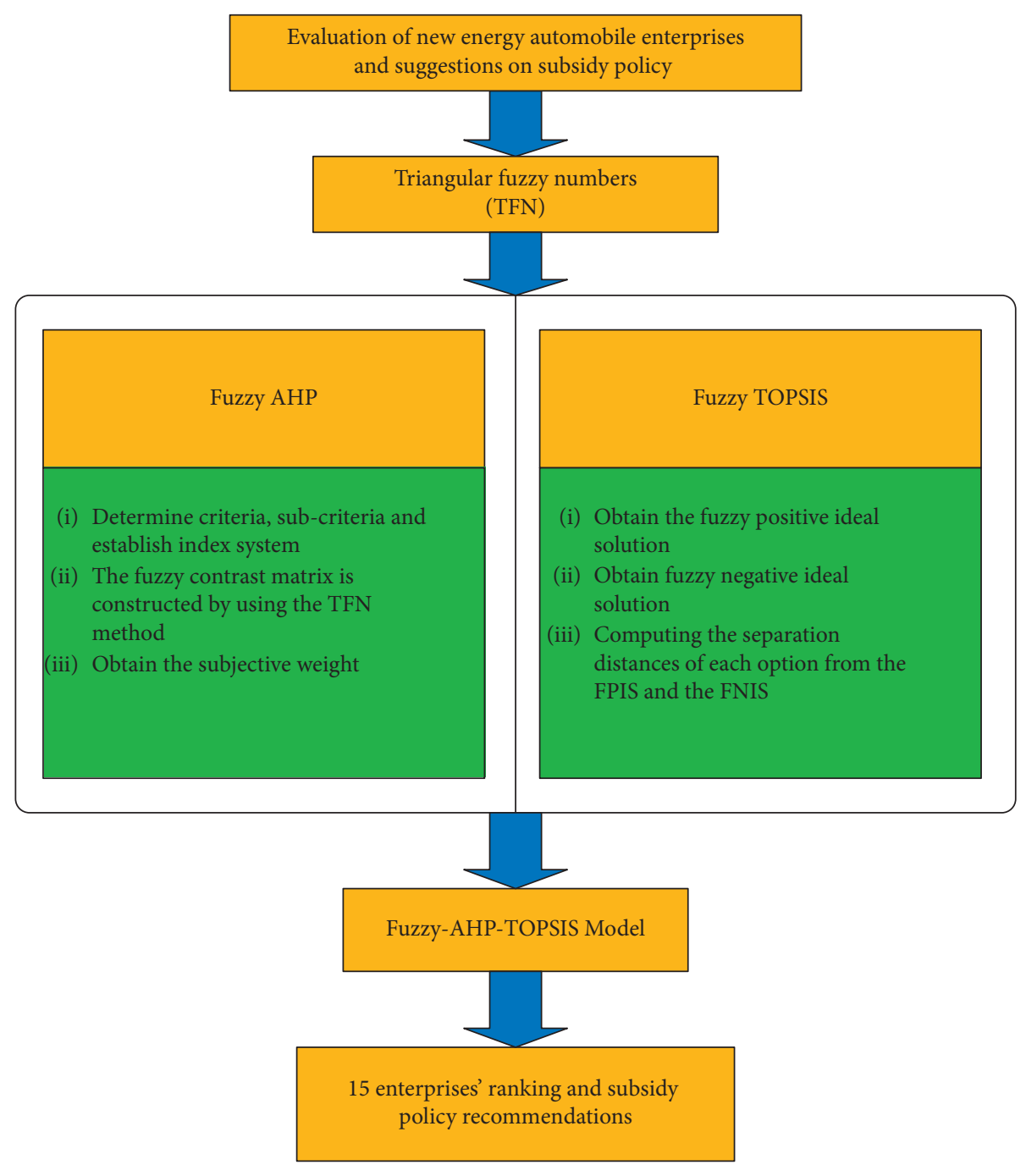

Figure 2: Article framework.

3.2. Evaluation Indicators System. By analyzing the existing evaluation index system of NEV enterprise, this paper sets the following three basic standards for comparison: (i) enterprise resource (ER), (ii) technical support (TS), and (iii) market capacity (MC). We define these three standards as follows.

3.2.1. Enterprise Resource. Enterprise resource is an indispensable index to measure a new energy automobile enterprise. It is the foundation of the business management activities. It includes the scale of employees, the ratio of high-quality personnel, the scale of fixed assets, and the advanced level of equipment.

3.2.2. Technical Support. Technical support is the core competitiveness of new energy automobile enterprises. As a product of advanced technology, technology determines the future development of new energy vehicles. This paper analyzes the technical support of enterprises from three aspects: adoption rate of new technology, the fund of R \& D, and level of R \& D team.

3.2.3. Market Capacity. Market capacity can reflect the market prospects of new energy vehicle companies. At the same time, the market is also the gear of the operation of the enterprise. This article considers from four aspects: price mechanism, brand awareness, turnover of capital, and aftersales service.

Under each of the three control criteria, eleven subcriteria are developed. The details of the subcriteria can be found in Appendix B of Supplementary Materials.

Therefore, the evaluation indicator system has been developed (see Figure 3).

\section{Method of Evaluation}

In this section, following the methods of Seyedmohammadi et al. in 2018 [22], we illustrate the concepts and steps of TFN, Fuzzy-AHP, and Fuzzy-TOPSIS. Then, 


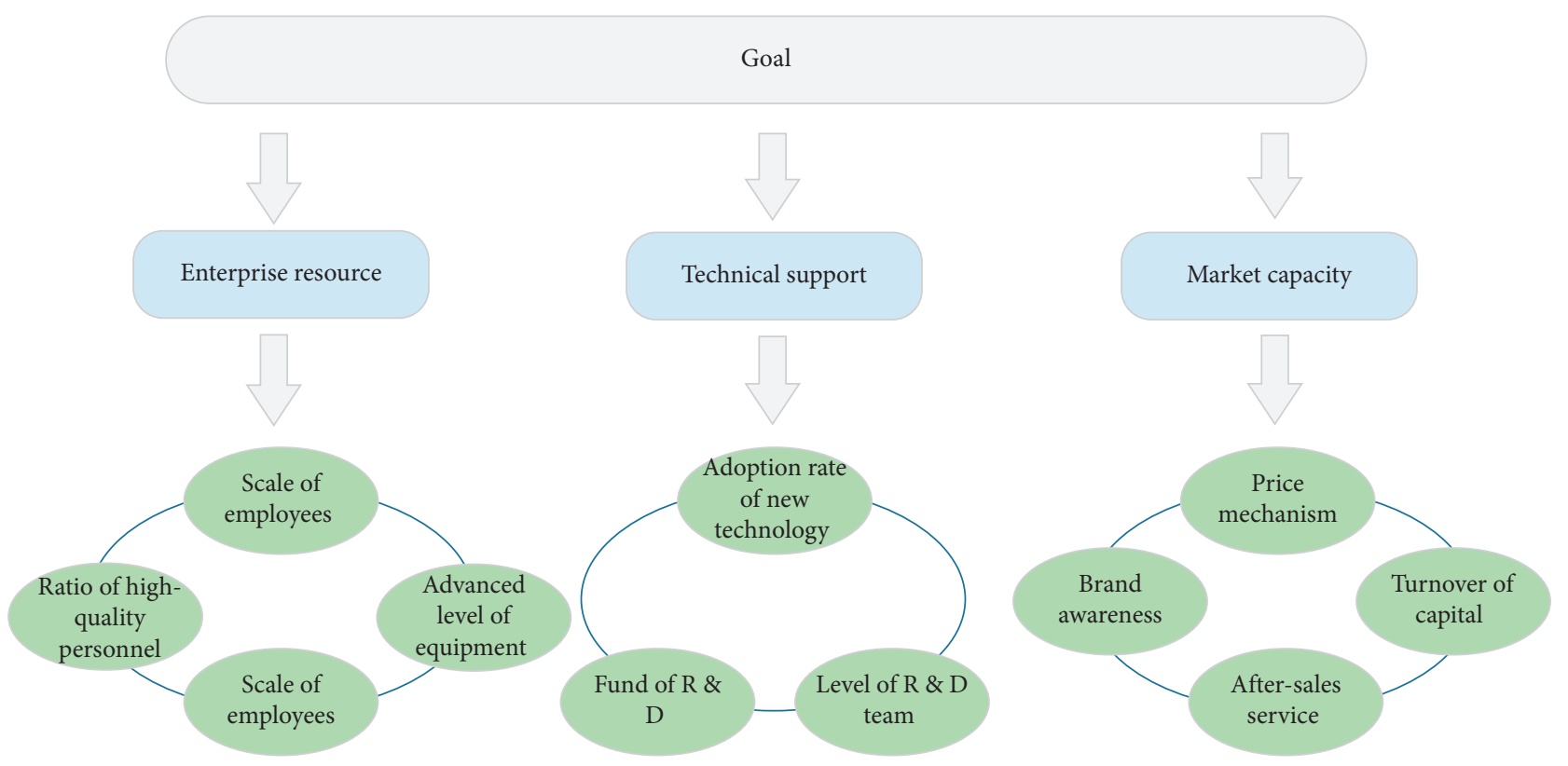

Figure 3: Index system of new energy automobile enterprises.

we use the TFN-AHP-TOPSIS model to evaluate $15 \mathrm{new}$ energy automobile enterprises. Finally, the evaluation results are analyzed to provide suggestions for the subsidy policy of China's new energy automotive industry. Our experimental results are calculated by MATLAB 2014A1.

4.1. TFN. In traditional decision-making problems, a fixed value is often used to evaluate, but this way makes the results not convincing. The emergence of TFN solves such uncertainty to a certain extent. TFN is a method to solve subjective decision-making problems. It is based on fuzzy sets and describes an uncertain value by three numbers. Because of the emergence of TFN, more choices are provided for experts to describe preferences, which make the data more reliable.

The membership functions of TFNs are as follows:

$$
\mu_{A}(x)= \begin{cases}0, & x \leq l, \\ \frac{x-l}{m-l}, & l<x \leq m, \\ \frac{x-u}{m-u}, & m<x \leq u, \\ 0, & x>u .\end{cases}
$$

$\widetilde{A}=(l, m, u)$ is a triangular fuzzy number, where $l$ is the smallest possible occurrence of the fuzzy number, that is, the lower limit of the fuzzy number; $u$ is the maximum possible occurrence of the fuzzy number, that is, the upper limit of the fuzzy number; and $m$ is the most likely value. The following describes the operation rules of triangular fuzzy numbers:

$$
\begin{aligned}
\widetilde{A}+B & =\left(a_{1}, a_{2}, a_{3}\right)+\left(b_{1}, b_{2}, b_{3}\right)=\left(a_{1}+b_{1}, a_{2}+b_{2}, a_{3}+b_{3}\right), \\
\widetilde{A} \times B & =\left(a_{1}, a_{2}, a_{3}\right) \times\left(b_{1}, b_{2}, b_{3}\right)=\left(a_{1} b_{1}, a_{2} b_{2}, a_{3} b_{3}\right), \\
\widetilde{A}^{-1} & =\left(\frac{1}{a_{1}}, \frac{1}{a_{2}}, \frac{1}{a_{3}}\right),
\end{aligned}
$$

where + denotes extended summation of two TFNs and $x$ denotes the extended multiplication.

4.2. Fuzzy AHP. The traditional AHP has been widely used in multiattribute decision making. Compared with other methods, AHP is easier to understand in mathematical calculation. Although AHP has been widely and successfully applied, it has been judged that it cannot solve the uncertainty caused by the association of the whole data with decision makers. Therefore, the application of traditional AHP is ineffective for the common fuzzy decision-making problems in real life. So the combination of fuzzy set theory and traditional AHP is very important to deal with uncertain data sources. The application of Fuzzy-AHP (Fuzzy-AHP), a fuzzy extension of analytic hierarchy process (AHP), can solve the problem of hierarchical division of fuzzy decision-making better. It allows decision makers to concentrate on specific subcriteria and make pairwise comparisons between criteria with the same hierarchy. In this way, the AHP method in the fuzzy environment can reduce the uncertainty of data sources and analysis results.

This paper obtains the value matrix by the TFN method, and then uses the method of Fuzzy-AHP to determine the weight of each index. The concrete steps are as follows: 
TABLE 1: Under the overall objective criterion pairwise comparison matrix.

\begin{tabular}{lcccr}
\hline Total goal & $E S$ & $T S$ & $M C$ & Weights \\
\hline$E S$ & $(1,1,1)$ & $(0.5,1.3,3)$ & $(0.5,1.4,5)$ & $(0.10,0.38,1.64)$ \\
$T S$ & $(0.33,1,2)$ & $(1,1,1)$ & $(0.33,1.3,3)$ & $(0.08,0.33,1.21)$ \\
$M C$ & $(0.2,0.87,2)$ & $(0.33,1,3)$ & $(1,1,1)$ & $(0.07,0.29,0.30)$ \\
$C R=0.01$ & & & & \\
\hline
\end{tabular}

TABle 2: Pairwise comparison matrix on enterprise resource.

\begin{tabular}{lccccc}
\hline ER & ER1 & ER2 & ER3 & ER4 & Weights \\
\hline ER1 & $(1,1,1)$ & $(0.33,0.77,2)$ & $(0.33,0.6,1)$ & $(0.33,0.6,2)$ & $(0.06,0.19,0.65)$ \\
ER2 & $(0.5,1.9,3)$ & $(1,1,1)$ & $(0.33,0.87,3)$ & $(1,1.2,2)$ & $(0.08,0.31,0.95)$ \\
ER3 & $(1,2.2,3)$ & $(0.33,1.9,3)$ & $(1,1,1)$ & $(0.3,1.7,3)$ & $(0.07,0.24,1.06)$ \\
ER4 & $(0.5,1.7,3)$ & $(0.5,0.8,1)$ & $(0.3,0.8,3)$ & $(1,1,1)$ & $(0.07,0.26,0.80)$ \\
CR $=0.01$ & & & & \\
\hline
\end{tabular}

TABle 3: Pairwise comparison matrix on technical support.

\begin{tabular}{lcccr}
\hline TS & TS1 & TS2 & TS3 & Weights \\
\hline TS1 & $(1,1,1)$ & $(0.33,0.5,1)$ & $(0.33,0.6,1)$ & $(0.11,0.21,0.44)$ \\
TS2 & $(1,2,3)$ & $(1,1,1)$ & $(1,1.2,2)$ & $(0.23,0.42,0.80)$ \\
TS3 & $(1,1.8,3)$ & $(0.5,0.9,1)$ & $(1,1,1)$ & $(0.19,0.37,0.63)$ \\
CR 0.00 & & & & \\
\hline
\end{tabular}

TABLe 4: Pairwise comparison matrix on market capacity.

\begin{tabular}{lccccc}
\hline$M C$ & $M C 1$ & $M C 2$ & $M C 3$ & MC4 & Weights \\
\hline$M C 1$ & $(1,1,1)$ & $(0.25,0.5,1)$ & $(0.33,0.8,2)$ & $(1,2,3)$ & $(0.07,0.17,0.62)$ \\
$M C 2$ & $(1,2,4)$ & $(1,1,1)$ & $(1,1.8,3)$ & $(1,3.2,5)$ & $(0.14,0.33,1.09)$ \\
$M C 3$ & $(0.5,1.4,3)$ & $(0.33,0.6,1)$ & $(1,1,1)$ & $(1,2.4,4)$ & $(0.09,0.21,0.73)$ \\
$M C 4$ & $(0.33,0.5,1)$ & $(0.2,0.32,1)$ & $(0.25,0.43,1)$ & $(1,1,1)$ & $(0.05,0.29,0.39)$ \\
$C R=0.02$ & & & &
\end{tabular}

Step 1: transform the linguistic preference description of experts into the form of fuzzy numbers, and the judgment matrix is obtained as follows:

$$
A=\left(\widetilde{a}_{i j}\right)_{n \times n}=\left[\begin{array}{cccc}
(1,1,1) & \left(l_{12}, m_{12}, u_{12}\right) & \cdots & \left(l_{1 n}, m_{1 n}, u_{1 n}\right) \\
\left(l_{21}, m_{21}, u_{21}\right) & (1,1,1) & \ldots & \left(l_{2 n}, m_{2 n}, u_{2 n}\right) \\
\vdots & \vdots & \ddots & \vdots \\
\left(l_{n 1}, m_{n 1}, u_{n 1}\right) & \left(l_{n 2}, m_{n 2}, u_{n 2}\right) & \cdots & (1,1,1)
\end{array}\right] .
$$

According to (3), the contrast matrix of control criterion and subcriteria is given by five experts, respectively (see Appendix A, Table A1-Table A20 in Supplementary Materials).

Step 2: integrate the evaluation matrices of the five experts by using the following equation:

$$
\left\{\begin{array}{l}
\widetilde{w}_{i j}=\left(L w_{i j}, M w_{i j}, U w_{i j}\right), \\
L w_{i j}=\min _{t}\left(l_{i j t}\right), M w_{i j}=\frac{1}{T} \sum_{t=1}^{T} m_{i j t}, U w_{i j}=\max _{t}\left(u_{i j t}\right),
\end{array}\right.
$$

where $\widetilde{w}_{i j}$ refers to the comparison between the $i^{\text {th }}$ criterion and the $j^{\text {th }}$ criterion after integration and
$L w_{i j}, M w_{i j}$, and $U w_{i j}$ refer to the lower limit, the average, and the upper limit of experts' score, respectively.

Then, the weight of the index is obtained (see Tables 1-4).

Step 3: determine the fuzzy weight of the indicators. The pairwise comparison matrix of the synthesis is calculated by the geometric mean method:

$$
\left\{\begin{aligned}
& w_{c 1}= r_{c 1} \times\left(r_{c 1}+r_{c 2}+\ldots+r_{c n}\right)^{-1}, \\
& w_{c 1}=\left(\begin{array}{c}
\left(L w_{g m c 1} \times\left(U w_{g m c 1}+\ldots+U w_{g m c n}\right)^{-1}\right) \\
\left(M w_{g m c 1} \times\left(M w_{g m c 1}+\ldots+M w_{g m c n}\right)^{-1}\right) \\
\left(U w_{g m c 1} \times\left(L w_{g m c 1}+\ldots+L w_{g m c n}\right)^{-1}\right)
\end{array}\right),
\end{aligned}\right.
$$

where $r_{i}$ refers to the geometric mean, $w_{c 1}$ refers to the fuzzy weight of first criterion, and $c 1$ refers to the first criterion in comparison matrix.

Then, the weight of all the indexes under the total goal is as follows (see Table 5).

4.3. Fuzzy TOPSIS. TOPSIS is a method proposed by Hwang and Yoon to solve multiattribute decision-making problems 
TABLE 5: The weight of all the indexes under the total goal.

\begin{tabular}{|c|c|c|c|c|}
\hline Criterion & Weights & Subcriterion & Weights & Weight under the overall goal \\
\hline \multirow{4}{*}{ Enterprise resource } & \multirow{4}{*}{$(0.10,0.38,1.64)$} & ER1 & $(0.06,0.19,0.65)$ & $(0.02,0.07,0.26)$ \\
\hline & & ER2 & $(0.08,0.31,0.95)$ & $(0.04,0.12,0.38)$ \\
\hline & & ER3 & $(0.07,0.24,1.06)$ & $(0.03,0.09,0.42)$ \\
\hline & & ER4 & $(0.07,0.26,0.80)$ & $(0.03,0.10,0.32)$ \\
\hline \multirow{3}{*}{ Technical support } & \multirow{3}{*}{$(0.08,0.33,1.21)$} & TS1 & $(0.11,0.21,0.44)$ & $(0.04,0.07,0.36)$ \\
\hline & & TS2 & $(0.23,0.42,0.80)$ & $(0.07,0.14,0.24)$ \\
\hline & & TS3 & $(0.19,0.37,0.63)$ & $(0.06,0.12,0.36)$ \\
\hline \multirow{4}{*}{ Market capacity } & \multirow{4}{*}{$(0.07,0.29,1.20)$} & $M C 1$ & $(0.07,0.17,0.62)$ & $(0.02,0.05,0.36)$ \\
\hline & & $M C 2$ & $(0.14,0.33,1.09)$ & $(0.04,0.10,0.36)$ \\
\hline & & $M C 3$ & $(0.09,0.21,0.73)$ & $(0.03,0.06,0.23)$ \\
\hline & & MC4 & $(0.05,0.29,0.39)$ & $(0.01,0.08,0.12)$ \\
\hline
\end{tabular}

[12]. It is used to select an optimal solution from a limited number of schemes. The principle of TOPSIS is to select a scheme with the shortest distance from the positive ideal solution and the farthest distance from the negative ideal solution among all the schemes, and then this scheme is the optimal solution. At the same time, we can rank the solutions according to the distance relationship between the solutions and the positive and negative ideal solutions, so as to solve the multiattribute decision-making problem. Chen proposed the fuzzy-TOPSIS technology, which solved the multiattribute decision-making problem in the fuzzy environment and effectively solved the uncertainty in the process of evaluation and judgment [23]. The core of this method is to find positive and negative ideal solutions based on data and use them as evaluation criteria. In order to solve the subjectivity, fuzziness, and imprecision of the subjective evaluation method, this paper adopts the Fuzzy-TOPSIS method, where the fuzzy number is a triangular fuzzy number [24].

The concrete calculate steps are as follows:

Step 1: establish the fuzzy value matrix by using (6), and the evaluation matrix of each enterprise is given by five experts:

$$
\overline{D M}=\left[\begin{array}{cccc}
\tilde{x}_{11} & \tilde{x}_{12} & \cdots & \tilde{x}_{1 n} \\
\tilde{x}_{21} & \tilde{x}_{22} & \cdots & \tilde{x}_{2 n} \\
\vdots & \vdots & \ddots & \vdots \\
\tilde{x}_{m 1} & \tilde{x}_{m 2} & \cdots & \tilde{x}_{m n}
\end{array}\right],
$$

where $\tilde{x}_{i j}$ is the aggregated fuzzy rating of $i^{\text {th }}$ option with respect to $j^{\text {th }}$ criterion and $i=1,2, \ldots, m$ and $j=1,2, \ldots, n$.

Fuzzy value matrix of Expert 1:

$$
\left.\begin{array}{|llllllllllll}
(5,6,6) & (5,5,6) & (4,4,5) & (5,6,7) & (5,6,8) & (6,6,7) & (5,6,7) & (7,7,8) & (7,7,8) & (6,7,7) & (5,7,7) \\
(3,4,4) & (4,5,6) & (4,5,6) & (4,5,6) & (3,5,6) & (4,4,5) & (3,4,5) & (6,7,7) & (3,4,4) & (3,6,6) & (4,7,7) \\
(5,6,7) & (6,7,9) & (6,8,9) & (7,7,8) & (7,8,9) & (5,6,7) & (6,7,7) & (6,6,7) & (5,7,9) & (5,6,7) & (5,6,8) \\
(4,6,7) & (4,4,5) & (3,4,5) & (5,5,7) & (4,5,5) & (4,5,6) & (3,5,6) & (4,5,7) & (5,6,7) & (6,7,7) & (5,6,8) \\
(4,5,6) & (4,4,5) & (4,4,5) & (3,3,5) & (2,3,5) & (3,4,5) & (3,4,4) & (5,6,7) & (5,5,7) & (4,5,5) & (5,5,7) \\
(4,4,6) & (4,5,6) & (3,6,7) & (4,6,7) & (5,5,8) & (5,6,7) & (5,6,7) & (6,6,6) & (4,5,7) & (6,7,8) & (5,5,5) \\
(4,4,5) & (3,5,6) & (2,3,5) & (3,4,5) & (3,5,6) & (4,5,6) & (4,5,6) & (5,7,7) & (4,5,6) & (5,6,7) & (5,5,7) \\
(3,4,5) & (5,6,6) & (5,5,6) & (3,4,5) & (5,7,8) & (3,4,5) & (4,4,5) & (5,6,7) & (3,4,5) & (6,7,8) & (4,6,7) \\
(2,3,4) & (3,5,5) & (2,4,5) & (3,5,5) & (5,6,7) & (1,3,4) & (2,3,5) & (4,6,6) & (4,5,6) & (4,5,6) & (5,6,7) \\
(3,5,5) & (4,5,6) & (4,5,7) & (3,5,6) & (3,6,6) & (4,5,6) & (4,5,6) & (3,4,5) & (4,5,7) & (5,7,7) & (5,6,6) \\
(3,4,5) & (5,6,7) & (4,5,6) & (3,4,5) & (4,5,6) & (3,4,5) & (3,4,5) & (4,5,6) & (3,4,5) & (5,6,7) & (6,7,7) \\
(5,6,7) & (5,6,7) & (4,5,6) & (6,7,7) & (5,6,7) & (6,7,8) & (5,6,7) & (5,5,7) & (6,6,7) & (6,7,8) & (5,6,7) \\
(4,6,6) & (4,5,5) & (4,7,7) & (5,5,6) & (3,5,5) & (3,5,5) & (4,5,6) & (4,5,5) & (3,5,6) & (4,6,6) & (5,6,7) \\
(2,3,3) & (3,4,4) & (3,4,5) & (5,5,6) & (3,4,5) & (4,4,5) & (3,4,6) & (4,6,6) & (4,4,6) & (5,6,7) & (5,6,6) \\
(4,5,6) & (3,5,6) & (4,5,6) & (4,5,6) & (5,6,7) & (5,6,7) & (5,5,6) & (4,6,7) & (5,6,7) & (5,6,7) & (5,6,6)
\end{array}\right) .
$$


Fuzzy value matrix of Expert 2:

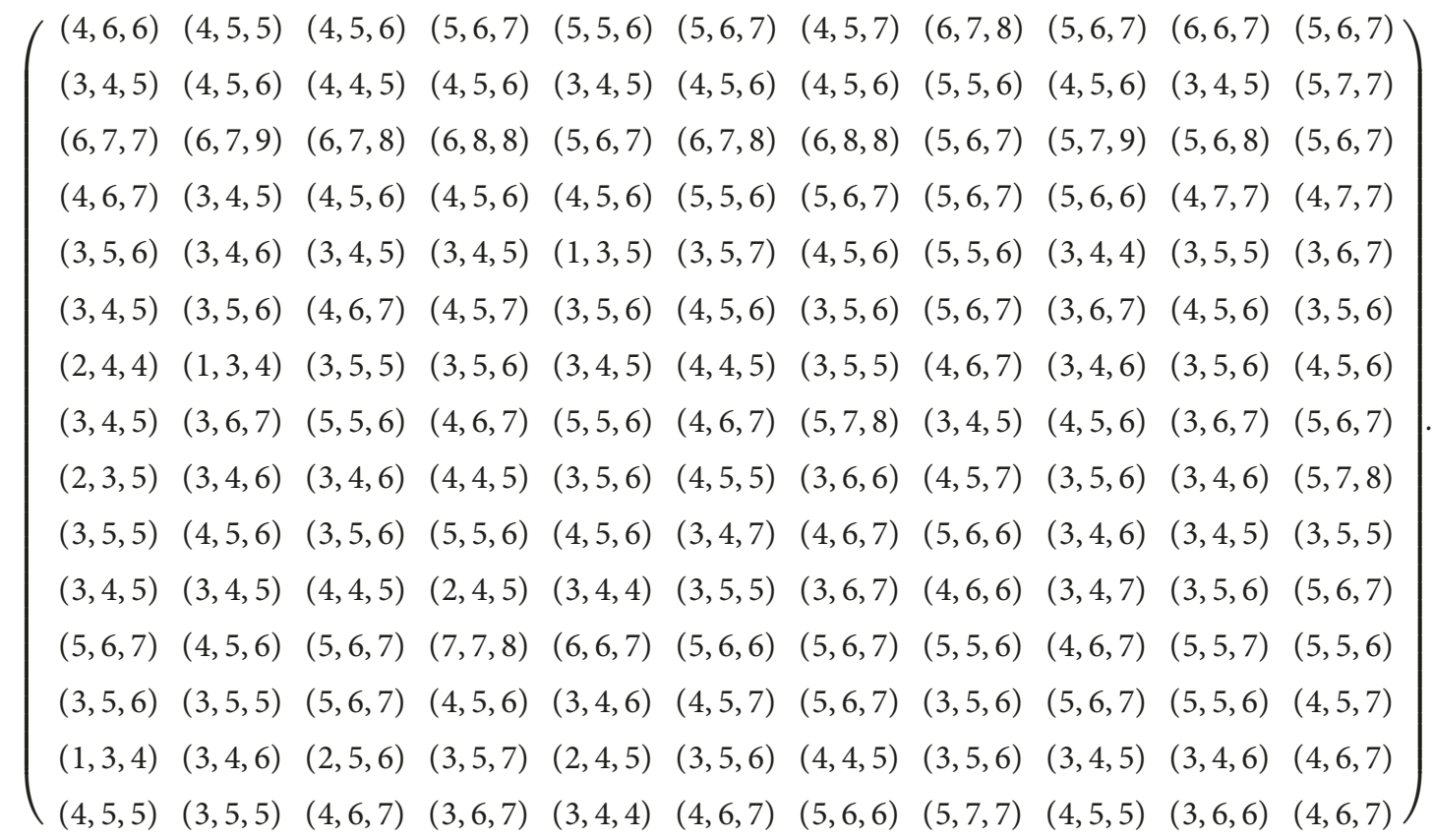

Fuzzy value matrix of Expert 3.

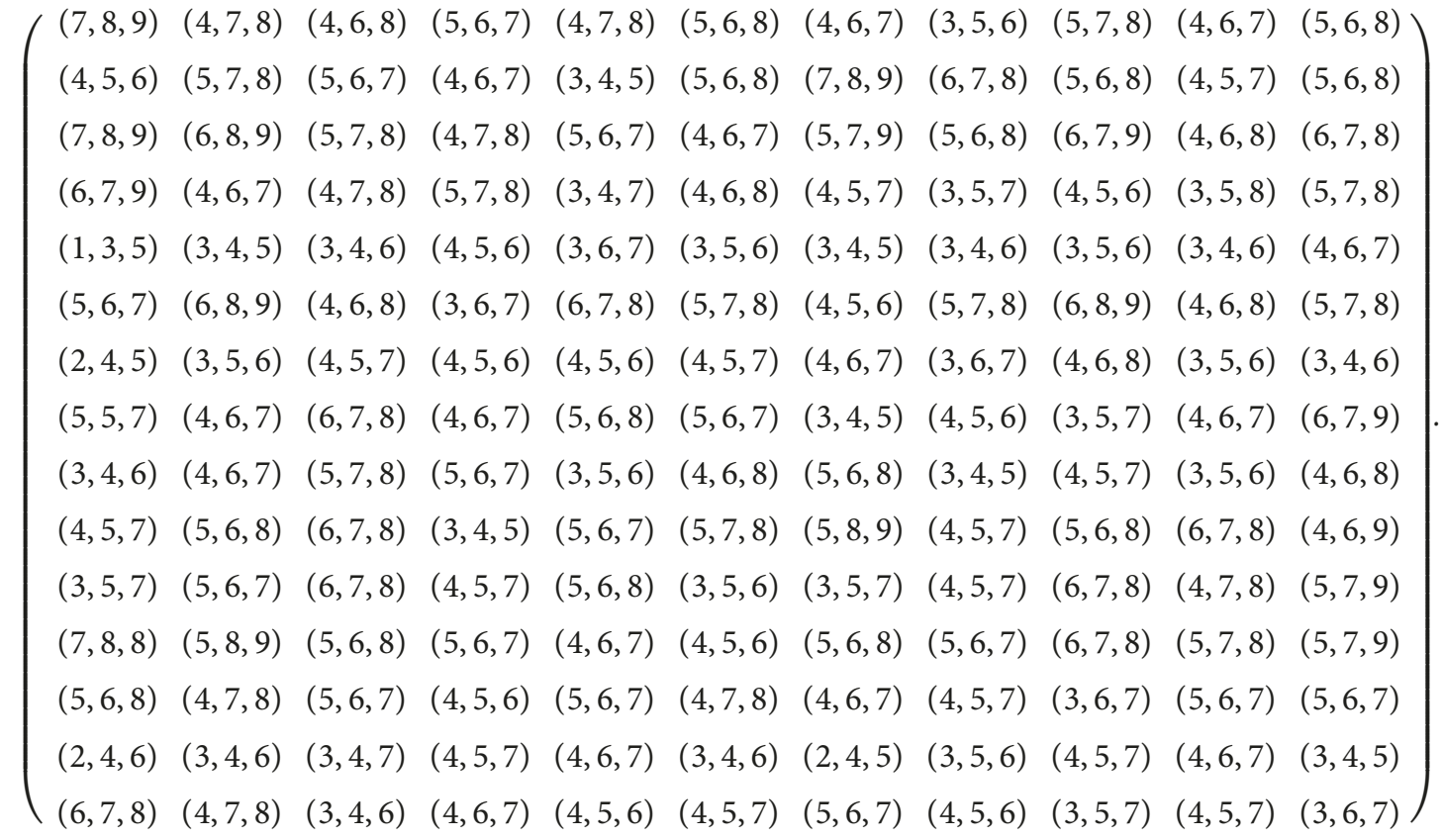




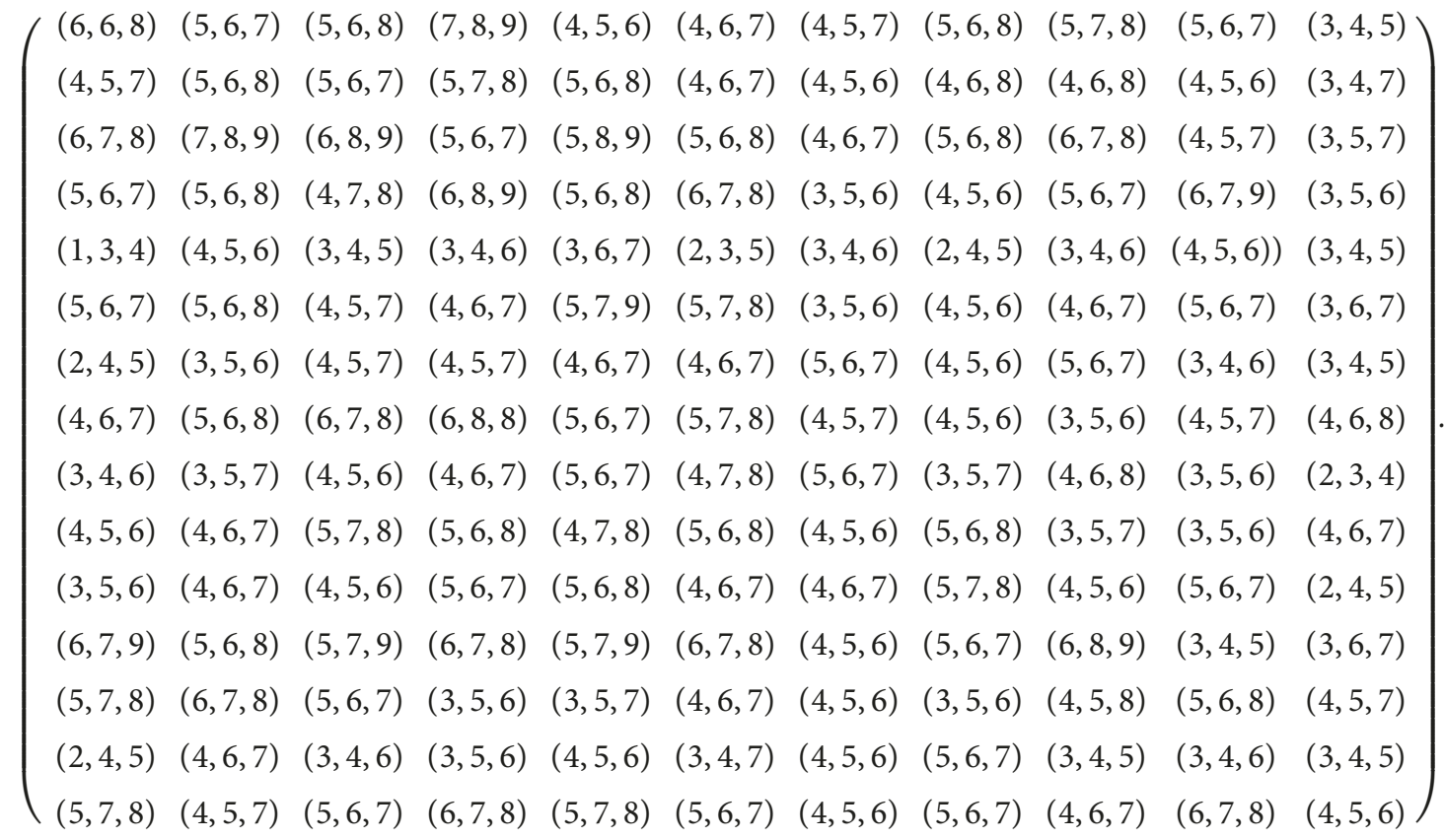

Fuzzy value matrix of Expert 5:

$$
\left.\begin{array}{|lllllllllll}
(4,5,7) & (4,6,6) & (4,4,5) & (4,6,8) & (4,5,6) & (6,6,7) & (4,5,5) & (5,7,7) & (4,5,7) & (4,5,7) & (5,6,6) \\
(3,4,6) & (4,5,5) & (4,4,5) & (3,3,5) & (4,5,7) & (4,6,7) & (3,4,5) & (4,5,7) & (3,4,6) & (3,4,5) & (4,4,6) \\
(6,7,9) & (4,6,9) & (7,8,8) & (6,8,9) & (3,6,6) & (5,7,9) & (6,7,8) & (4,6,7) & (6,8,9) & (5,7,7) & (4,6,7) \\
(5,6,6) & (5,7,7) & (3,4,5) & (4,6,7) & (3,5,5) & (5,7,7) & (3,5,6) & (4,6,6) & (4,7,8) & (4,5,6) & (5,7,7) \\
(4,5,6) & (2,3,4) & (2,2,4) & (4,4,5) & (1,2,3) & (3,4,5) & (2,3,4) & (1,2,3) & (2,4,5) & (3,3,4) & (2,3,5) \\
(3,4,6) & (4,5,8) & (5,6,7) & (4,4,5) & (5,7,8) & (6,6,7) & (5,6,8) & (5,7,9) & (5,5,7) & (6,7,8) & (5,7,8) \\
(3,4,5) & (3,4,5) & (2,3,5) & (1,3,5) & (2,4,5) & (4,5,6) & (5,6,7) & (3,4,6) & (1,3,5) & (2,3,4) & (3,4,5) \\
(4,4,5) & (4,5,6) & (4,5,6) & (4,4,6) & (4,5,6) & (4,5,6) & (3,4,5) & (5,6,7) & (4,5,6) & (5,5,6) & (4,5,7) \\
(2,3,5) & (2,5,5) & (3,4,6) & (3,6,6) & (5,5,6) & (5,6,7) & (3,4,6) & (4,4,6) & (3,5,6) & (4,5,6) & (1,3,5) \\
(4,5,6) & (3,4,5) & (4,5,6) & (3,4,4) & (2,3,5) & (3,4,5) & (1,3,5) & (2,4,6) & (2,3,4) & (2,4,5) & (4,5,7) \\
(3,4,5) & (1,3,5) & (2,5,6) & (4,6,7) & (4,5,7) & (2,3,5) & (3,4,6) & (5,5,7) & (2,3,6) & (1,2,4) & (3,4,5) \\
(5,6,6) & (3,5,7) & (4,5,7) & (5,7,9) & (4,5,7) & (6,7,7) & (5,5,6) & (3,5,6) & (4,6,7) & (5,7,8) & (5,5,6) \\
(5,6,7) & (3,4,5) & (5,7,7) & (3,5,5) & (4,5,6) & (3,5,7) & (4,5,7) & (3,5,6) & (4,5,7) & (3,6,7) & (5,6,7) \\
(2,3,4) & (2,4,5) & (3,4,6) & (2,2,2) & (3,3,4) & (3,4,6) & (3,5,6) & (4,4,5) & (3,3,5) & (4,4,5) & (3,3,4) \\
(5,6,6) & (5,7,7) & (3,4,5) & (4,6,7) & (3,5,5) & (5,7,7,) & (3,5,6) & (4,6,6) & (4,7,8) & (4,5,6) & (5,7,7)
\end{array}\right) .
$$

Step 2: aggregate the ratings of 15 enterprises, and build and normalize the fuzzy decision matrix from the aggregated ratings. The normalization of the decision matrix $\overline{D M}$ can be carried out by the following equations (see Appendix C, Table C1, and Table C2 in Supplementary Materials):

$$
\begin{gathered}
c_{j}^{+}=\operatorname{Max}\left(U x_{i j}\right), \quad j \in B ; \\
\bar{u}_{i j}=\left(\frac{L x_{i j}}{c_{j}^{+}}, \frac{M x_{i j}}{c_{j}^{+}}, \frac{U x_{i j}}{c_{j}^{+}}\right),
\end{gathered}
$$

where $c_{j}^{+}$denotes the maximum value of the upper limit 
of triangular fuzzy number of all schemes under the $j^{\text {th }}$ index of the decision matrix. Finally, the standardized decision matrix can be expressed as follows:

$$
\widetilde{U}=\left[\begin{array}{cccc}
\tilde{u}_{11} & \tilde{u}_{12} & \cdots & \widetilde{u}_{1 n} \\
\widetilde{u}_{21} & \widetilde{u}_{22} & \cdots & \widetilde{u}_{2 n} \\
\vdots & \vdots & \ddots & \vdots \\
\tilde{u}_{m 1} & \widetilde{u}_{m 2} & \cdots & \widetilde{u}_{m n}
\end{array}\right]
$$

Step 3: calculate the fuzzy weighted normalized decision matrix by multiplying the weights of the evaluation criteria $\widetilde{w}_{j}$ by the elements of the normalized fuzzy decision matrix $u_{i j}$ according to the following equation (see Appendix C and Table C3 in Supplementary Materials):

$\widetilde{v}_{i j}=\widetilde{u}_{i j} \times \widetilde{w}_{j}=\left(\frac{L x_{i j}}{c_{j}^{+}}, \frac{M x_{i j}}{c_{j}^{+}}, \frac{U x_{i j}}{c_{j}^{+}}\right) \times\left(w_{1}, w_{2}, w_{3}\right)$, where $\widetilde{w}_{j}$ is the index weight obtained by Fuzzy-AHP. Finally, the matrix is recorded as follows:

$$
\widetilde{V}=\widetilde{U} \times \tilde{W}=\left[\begin{array}{cccc}
\tilde{v}_{11} & \widetilde{v}_{12} & \cdots & \widetilde{v}_{1 n} \\
\widetilde{v}_{21} & \widetilde{v}_{22} & \cdots & \widetilde{v}_{2 n} \\
\vdots & \vdots & \ddots & \vdots \\
\tilde{v}_{m 1} & \tilde{v}_{m 2} & \cdots & \widetilde{v}_{m n}
\end{array}\right] .
$$

Step 4: define the fuzzy positive ideal solution (FPIS $S^{+}$) and the fuzzy negative ideal solution (FNIS, $S^{-}$) according to the following equations:

$$
\begin{aligned}
& S^{+}=\left(\widetilde{v}_{1}^{+}, \widetilde{v}_{2}^{+}, \ldots, \widetilde{v}_{n}^{+}\right), \\
& \widetilde{v}_{j}^{+}=\left(\operatorname{Max} L v_{i j}, \operatorname{Max} M v_{i j}, \operatorname{Max} U v_{i j}\right), \\
& S^{-}=\left(\widetilde{v}_{1}^{-}, \widetilde{v}_{2}^{-}, \ldots, \widetilde{v}_{n}^{-}\right), \\
& \widetilde{v}_{j}^{-}=\left(\operatorname{Min} L v_{i j}, \operatorname{Min} M v_{i j}, \operatorname{Min} U v_{i j}\right) .
\end{aligned}
$$

Obtain

$$
\begin{aligned}
S^{+}= & ((0.02,0.07,0.26)(0.04,0.12,0.38)(0.03,0.09,0.42)(0.03,0.10,0.32)(0.04,0.07,0.36)(0.07,0.14,0.36)(0.06,0.12,0.36) \\
& (0.02,0.05,0.36)(0.04,0.10,0.36)(0.03,0.06,0.23)(0.01,0.08,0.12)), \\
S^{-}= & ((0.01,0.03,0.16)(0.02,0.07,0.23)(0.01,0.04,0.25)(0.02,0.06,0.22)(0.02,0.04,0.25)(0.04,0.09,0.26)(0.03,0.07,0.23) \\
& (0.01,0.03,0.26)(0.02,0.06,0.23)(0.02,0.04,0.16)(0.01,0.06,0.09)) .
\end{aligned}
$$

Step 5: compute the separation distances of each option from FPIS and FNIS to provide a measure according to
(19) and (20), which provide separation distance for two TFNs by the vertex method:

$$
\begin{aligned}
& \mathrm{d}\left(\widetilde{v}_{i j}, \widetilde{v}_{j}^{+}\right)=\sqrt{\frac{1}{3}\left[\left(L v_{i j}-\max L v_{i j}\right)^{2}+\left(M v_{i j}-\max M v_{i j}\right)^{2}+\left(U v_{i j}-\max U v_{i j}\right)^{2}\right]}, \\
& \mathrm{d}\left(\widetilde{v}_{i j}, \widetilde{v}_{j}^{-}\right)=\sqrt{\frac{1}{3}\left[\left(L v_{i j}-\min L v_{i j}\right)^{2}+\left(M v_{i j}-\min M v_{i j}\right)^{2}+\left(U v_{i j}-\min U v_{i j}\right)^{2}\right]}
\end{aligned}
$$

Then, $D_{i}^{+}=\sum \mathrm{d}\left(\widetilde{v}_{i j}, \widetilde{v}_{j}^{+}\right), \quad D_{i}^{-}=\sum \mathrm{d}\left(\widetilde{v}_{i j}, \widetilde{v}_{j}^{-}\right), \quad i=1,2, \quad$ So we get $\ldots, m, j=1,2, \ldots, n$. 


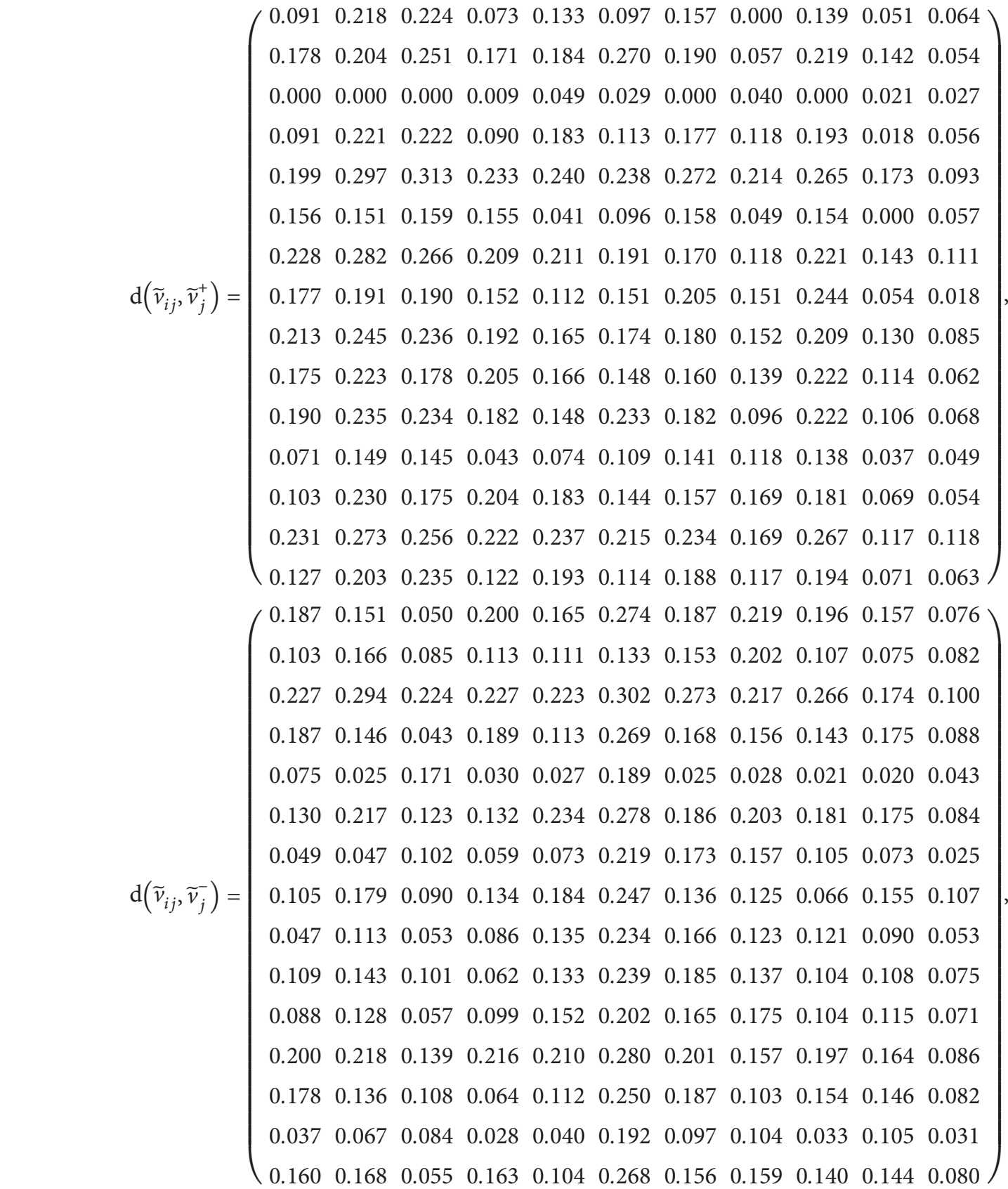

$$
\begin{aligned}
& D_{i}^{+}=(1.246,1.919,0.175,1.482,2.537,1.175,2.151,1.645,1.980,1.792,1.895,1.073,1.670,2.336,1.627) \text {, } \\
& D_{i}^{-}=(1.862,1.329,2.528,1.676,0.655,1.944,1.083,1.528,1.221,1.396,1.355,2.068,1.521,0.818,1.595) \text {. }
\end{aligned}
$$

Step 6: compute the relative closeness coefficient $\left(\mathrm{CC}_{i}\right)$ of each option with respect to (FPIS, $S^{+}$) and (FPIS, $S^{-}$) by using the following equation:

$$
\mathrm{CC}_{i}=\left[\frac{D_{i}^{-}}{D_{i}^{+}+D_{i}^{-}}\right]=(0.599,0.409,0.935,0.531,0.205,0.623,0.335,0.482,0.381,0.438,0.417,0.658,0.477,0.259,0.495)
$$




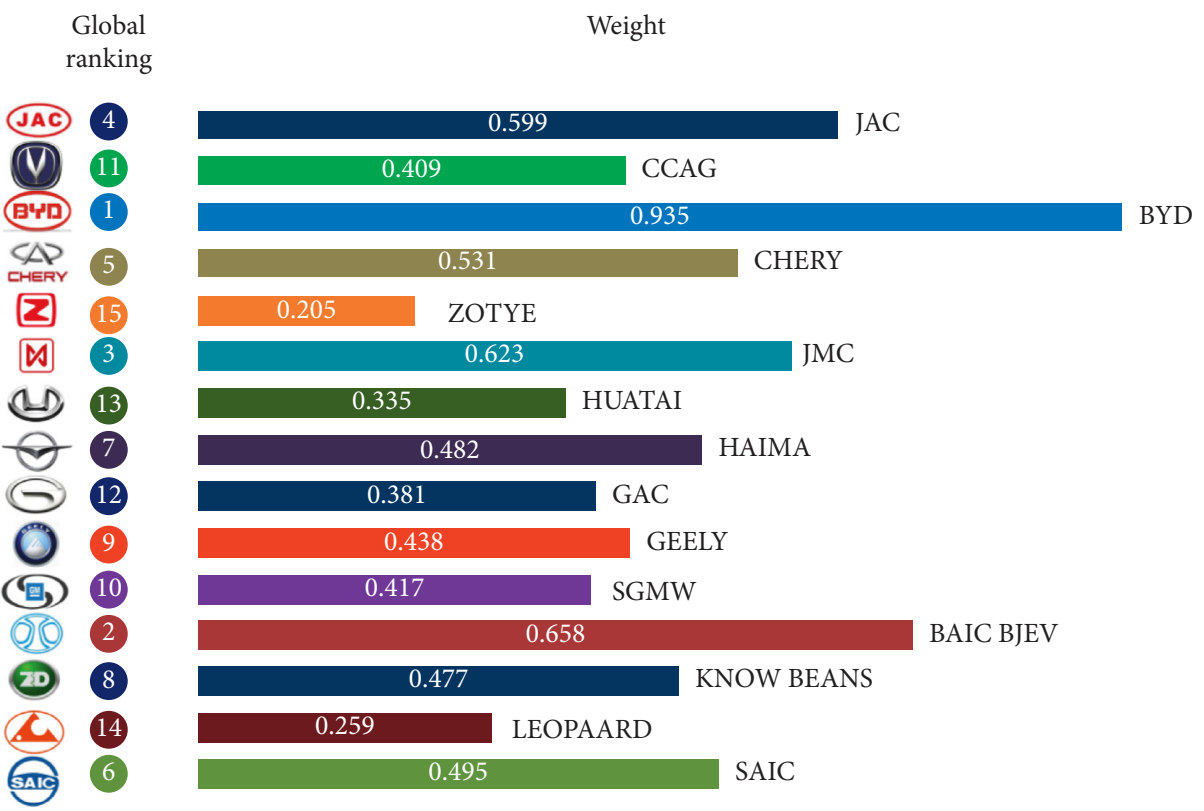

FIgURE 4: Scores and rankings of each new energy automobile enterprise.

Finally, the ranking and comprehensive score of fifteen new energy automobile enterprises were obtained (see Figure 4).

4.4. Result Analysis and Subsidy Policy Suggestion. This ranking is analyzed from three aspects: enterprise resources, technology, and market (see Figure 5). It can roughly determine the overall situation of each enterprise (including the comprehensive strength of enterprises and the risk of subsidy fraud).

So according to the ranking of enterprises, this paper sets up the differential subsidy amount on the basis of the original subsidy policy. Therefore, we can not only comply with the new policy of "Support the strong and Strengthen the strong" in the new energy auto industry of China, but also can reduce the risk of subsidy fraud and reduce the amount of loss caused by fraud [25].

First, we need to establish a measurement standard, so we use the RSR (rank-sum ratio) method to group 15 enterprises. The RSR method was proposed by Tian [26], a Chinese scholar, in 1988, which combines statistical advantages of classical parameter estimation and modern nonparametric statistics. After more than thirty years of development, the method has been gradually perfected with the common support and efforts of the vast majority of scholars. It has the characteristics of strong pertinence, simple operation, and obvious use effect, which is widely used in the fields of health management, hospital management, and medical quality control.

We use the score of enterprise to replace the RSR values and rank them from small to large, then list the frequency $f$ of the different groups and the cumulative frequency $\sum f$, and get the rank $R$ and the average rank $\bar{R}$ in each group. Finally, we calculate the cumulative frequency $P=\bar{R} / n \times$ $100 \%$ ( $n$ represents enterprise number), and the corresponding probability unit value (Probit) is obtained in Table 6.

According to Table 7, 15 new energy automobile enterprises are divided into 3 groups according to the RSR estimation value obtained by regression equation.

First group: (BYD, 0935) (BAIC BJEV, 0.658).

Second group: (JMC, 0.623) (JAC, 0.599) (CHERY, 0.531) (SAIC, 0.495) (HAIMA, 0.482) (KNOW BEANS,

0.477) (GEELY, 0.438) (SGMW, 0.417) (CCAG, 0.409) (GAC, 0.381).

Third group: (HUATAI, 0.335) (LEOPAARD, 0.259) (ZOTYE, 0.205).

Step 1: take out the average value of each group.

The first group: average $\mathrm{first}=0.797$.

The second group: average second $=0.485$.

The third group: average $e_{\text {third }}=0.266$.

Step 2: the average value of the calculated results in Step 2:

The average number is average score $=0.516$.

As shown in Figure 6, we use the above average score $_{\text {as }}$ a measure of the standard.

So, the NEV of a certain model of the $x$ enterprise is

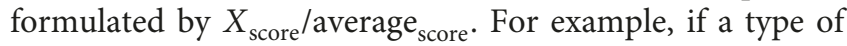
$\mathrm{NEV}$ is subsidized for ten thousand yuan per unit, the subsidy amount for the same type of NEV in the JMC, which is ranked fourth in the ranking, is $\mathrm{JMC}_{\text {score }}$ /average score $\times$ $10000=0.623 / 0.516 \times 10000=12074$ yuan per unit. In the same assessment, the subsidy amount for the same type of $\mathrm{NEV}$ in the GAC, which is ranked fourth in the ranking, is $\mathrm{GAC}_{\text {score }}$ /average $_{\text {score }} \times 10000=0.381 / 0.516 \times 10000=$ 7384 yuan per unit (Figure 7 is the ratio of 15 enterprises to average). This differentiated subsidy policy can stimulate 


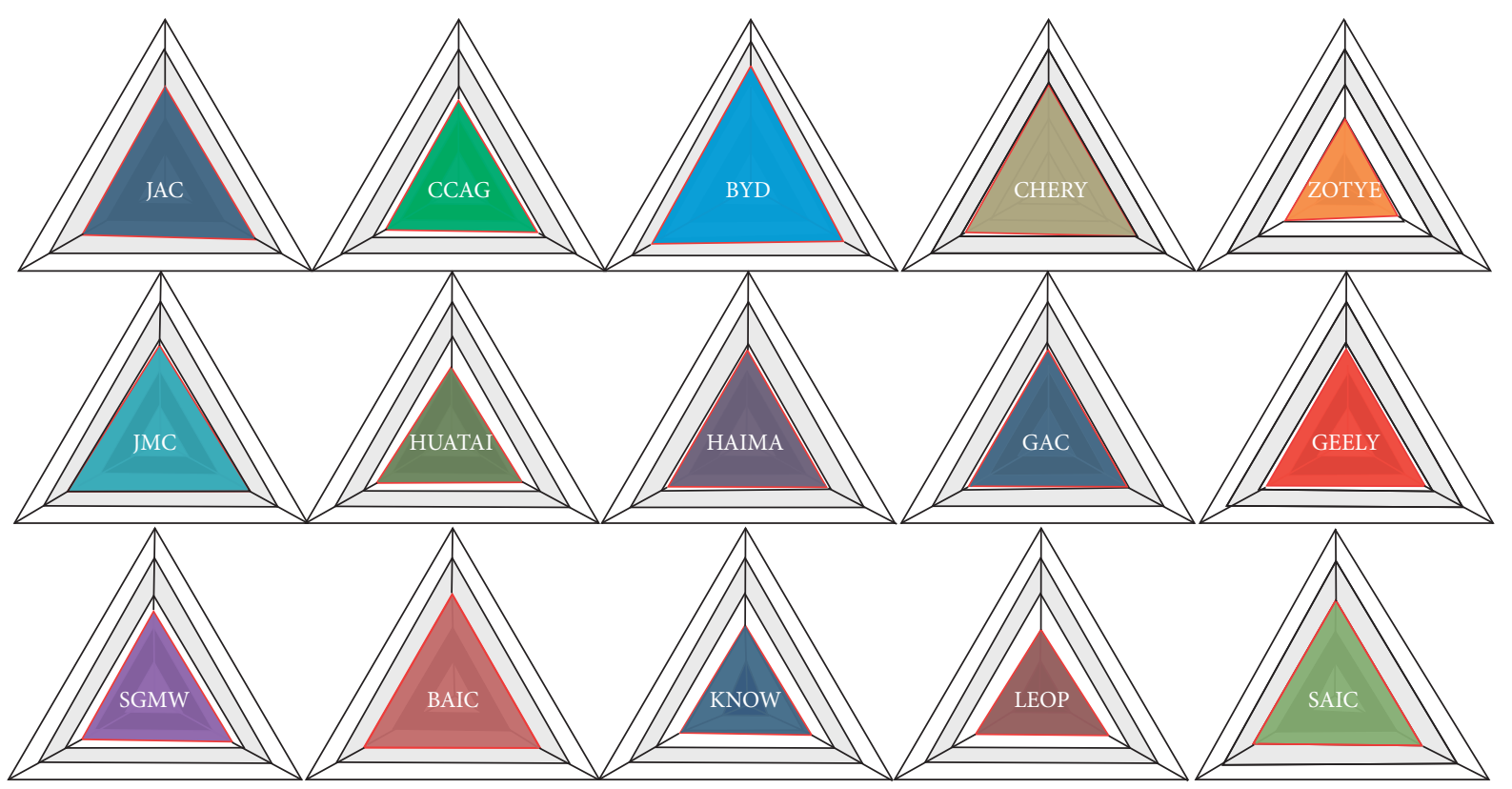

FIgURE 5: The radar chart of the performance of NEV enterprises in three aspects.

TABLE 6: Enterprises RSR distribution and the corresponding probit.

\begin{tabular}{|c|c|c|c|c|c|c|}
\hline Enterprise & $D(R S R)$ & $f$ & $\Sigma f$ & $R$ & $P(\%)$ & Probit \\
\hline$B Y D$ & 0.935 & 1 & 1 & 1 & 6.67 & 3.445 \\
\hline BAIC BJEV & 0.658 & 1 & 2 & 2 & 13.33 & 3.825 \\
\hline$J M C$ & 0.623 & 1 & 3 & 3 & 20.00 & 4.158 \\
\hline$J A C$ & 0.599 & 1 & 4 & 4 & 26.67 & 4.357 \\
\hline CHERY & 0.531 & 1 & 5 & 5 & 33.33 & 4.560 \\
\hline SAIC & 0.495 & 1 & 6 & 6 & 40.00 & 4.747 \\
\hline Haima & 0.482 & 1 & 7 & 7 & 46.67 & 4.900 \\
\hline KNOW BEANS & 0.477 & 1 & 8 & 8 & $53.33 \%$ & 5.075 \\
\hline GEELY & 0.438 & 1 & 9 & 9 & 60.00 & 5.253 \\
\hline SGMW & 0.417 & 1 & 10 & 10 & 66.67 & 5.413 \\
\hline$C C A G$ & 0.409 & 1 & 11 & 11 & 73.33 & 5.613 \\
\hline$G A C$ & 0.381 & 1 & 12 & 12 & 80.00 & 5.842 \\
\hline HUATAI & 0.335 & 1 & 13 & 13 & 86.67 & 6.080 \\
\hline LEOPAARD & 0.259 & 1 & 14 & 14 & 93.33 & 6.476 \\
\hline ZOTYE & 0.205 & 1 & 15 & 15 & $98.33^{*}$ & 7.054 \\
\hline
\end{tabular}

*Estimated by $[1-1 / 4 \times n]$.

TABLE 7: Critical probit values for different commonly used grade numbers.

\begin{tabular}{lc}
\hline Group number & Probit \\
\hline 3 & $4.00,6.00$ \\
4 & $3.50,5.00,6.50$ \\
5 & $3.20,4.40,5.60,6.80$ \\
6 & $3.00,4.00,5.00,6.00,7.00$ \\
7 & $2.86,3.72,4.57,5.44,6.28,7.14$ \\
\hline
\end{tabular}

competition among enterprises, accelerate technological innovation, and promote the development of the new energy automobile industry.

Based on the above, we will redistribute the subsidy amount on the basis of the original policy so as to reduce the economic losses caused by fraud. This proposal is based on the comprehensive strength of the enterprises in three aspects so as to improve the entrance threshold of new energy automobile enterprises and products, thus stimulate competition among enterprises, accelerate technological innovation, and promote the development of new energy auto industry [27].

\section{Conclusion}

In order to promote the rapid development of China's new energy automobile industry and solve the domestic energy and environmental problems, the government has promulgated many supporting policies. But driven by profits, some new energy automobile companies began to cheat the state's financial subsidies. This phenomenon seriously damages the rights and interests of the government and the 


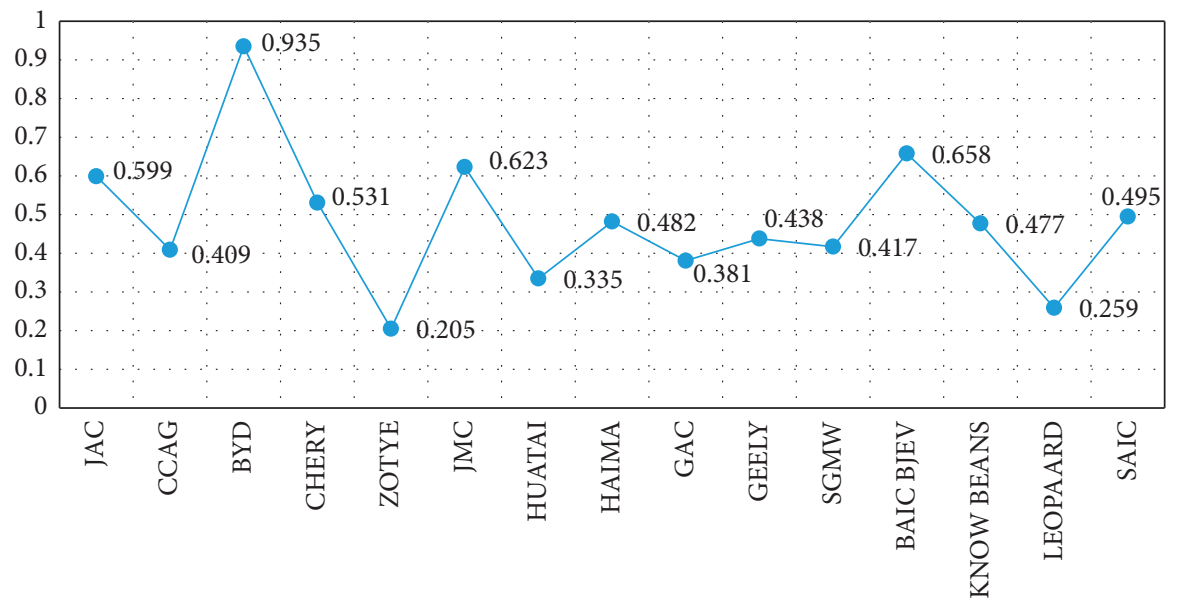

FIGURE 6: The performance of NEV enterprises.

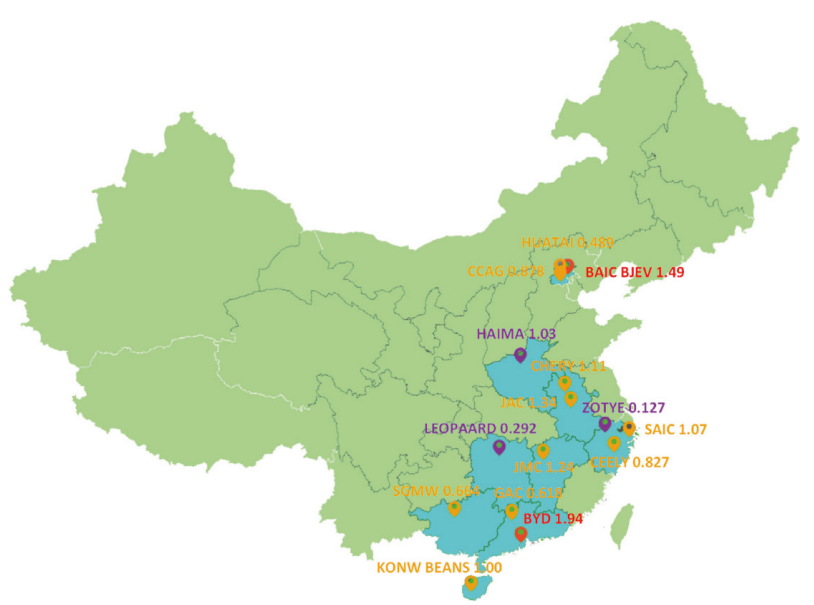

Figure 7: Proportion of the amount of subsidies for 15 enterprises.

people, and at the same time hinders the healthy development of the new energy automobile industry. We can see from the past year's production and sales that the exposure of the "subsidy fraud" problem has greatly reduced the growth rate of domestic production and sales of new energy vehicles. This problem is caused by the insufficient supervision of the relevant government and the low threshold of subsidies. This paper evaluates 15 new energy automobile companies and then formulates a differentiated subsidy policy according to the ranking, which provides new ideas for the formulation of new subsidy policy.

Firstly, the TFN-AHP-TOPSIS model is used to evaluate 15 new energy automobile enterprises. The model makes use of its scientific, accurate, and flexible characteristics to make the evaluation results more reliable. Among them (1) TFN provides a vague decision-making environment. In the process of preference selection by the expert group, it is often impossible to evaluate an object with certain values, but the fuzzy number can effectively solve this problem. Therefore, the use of TFN can reduce the uncertainty of subjective evaluation. (2) Fuzzy-AHP determines the weight of indicators in a subjective way. Different from traditional AHP, Fuzzy-AHP can solve the problem of weight determination in fuzzy environment. This paper analyses the new energy automobile enterprises from three aspects: enterprise resources, technology support, and market capacity, then constructs the index system, and finally determines the fuzzy weight of the index. (3) Fuzzy-TOPSIS determines the final score and ranking of enterprises. TOPSIS determines the comprehensive score by the distance between each evaluation object and FPIS and FNIS. At the same time, the perfect combination of Fuzzy-TOPSIS and TFN transforms the fuzzy number into a deterministic number. In the follow-up study, from the methodological level, we can do more in-depth research. We should consider the interactions among the criteria, and the analytic network process (ANP) method may be more appropriate. ANP not only solves the issues that can be solved by AHP but also considers the interaction with and dependency on each influencing factor in decision-making.

Secondly, 15 enterprises are grouped by the RSR method to determine a measurement standard. And a differential subsidy policy is formulated according to the standard and the enterprise's comprehensive score. In this way, we can not only improve the access threshold of subsidies, but also strengthen the benign competition in the new energy automobile market. It makes Chinese automobile enterprises devote themselves to the research and development of new energy automobile key technology and the improvement of enterprise reputation and vehicle performance-price ratio, thus making China's new energy automobile industry develop healthily and rapidly.

Finally, we need to affirm that the ranking summarized in this paper cannot be considered the only solution because there are many subjective factors, such as different indicator systems and methods, may lead to different results. This paper only provides a useful reference for the development of new energy automobile industry, hoping to provide help for the development of the new energy automobile industry.

\section{Data Availability}

The data used to support the findings of this study are available from the corresponding author upon request. 


\section{Conflicts of Interest}

The authors declare no conflicts of interest.

\section{Authors' Contributions}

Xiaojia Wang and Yiming Song conceived and designed the experiments; Yiming Song contributed analysis tools; Xuan Zhang assisted in building the data set; and Hui Liu helped common on this article.

\section{Acknowledgments}

This paper was supported by the National Natural Science Foundation of China (Grant Nos.61876055 and 71101041); the National Statistics Research Projects (Grant no. 2013LZ07); and the Special Foundation of Doctorate Personnel of Hefei University of Technology (Grant no. 2012HGBZ0647).

\section{Supplementary Materials}

Appendix A contains the contrast matrix of the control criterion and subcriteria given by five experts. Appendix B shows the details of the subcriteria. Appendix C contains normalized decision matrix and normalized fuzzy decision matrix. (Supplementary Materials)

\section{References}

[1] X. Wang, Y. Song, W. Xia, H. Liu, and S. Yang, "Promoting the development of the new energy automobile industry in China: technology selection and evaluation perspective," Journal of Renewable and Sustainable Energy, vol. 10, no. 4, Article ID 045901, 2018.

[2] X. Yuan, X. Liu, and J. Zuo, "The development of new energy vehicles for a sustainable future: a review," Renewable and Sustainable Energy Reviews, vol. 42, pp. 298-305, 2015.

[3] Y. Hao, X.-Y. Dong, Y.-X. Deng, L.-X. Li, and Y. Ma, "What influences personal purchases of new energy vehicles in China? An empirical study based on a survey of Chinese citizens," Journal of Renewable \& Sustainable Energy, vol. 8, no. 6, Article ID 065904, 2016.

[4] S. M. Hakimi and S. M. Moghaddastafreshi, "Effect of plug-in hybrid electric vehicles charging/discharging management on planning of smart microgrid," Journal of Renewable \& Sustainable Energy, vol. 4, no. 6, Article ID 063144, 2012.

[5] L. Zadeh, "Fuzzy sets," Information and Control, vol. 8, no. 3, pp. 338-353, 1965.

[6] P. J. M. Van Laarhoven and W. Pedrycz, "A fuzzy extension of Saaty's priority theory,” Fuzzy Sets \& Systems, vol. 11, no. 1-3, pp. 199-227, 1983.

[7] Q. An, F. Meng, and B. Xiong, "Interval cross efficiency for fully ranking decision making units using DEA/AHP approach," Annals of Operations Research, vol. 271, no. 2, pp. 297-317, 2018.

[8] D.-Y. Chang, "Applications of the extent analysis method on fuzzy AHP," European Journal of Operational Research, vol. 95, no. 3, pp. 649-655, 1996.

[9] Y.-M. Wang, Y. Luo, and Z. Hua, "On the extent analysis method for fuzzy AHP and its applications," European Journal of Operational Research, vol. 186, no. 2, pp. 735-747, 2008.
[10] L. Mikhailov, "Deriving priorities from fuzzy pairwise comparison judgements," Fuzzy Sets and Systems, vol. 134, no. 3, pp. 365-385, 2003.

[11] J. Rezaei, R. Ortt, and V. Scholten, "An improved fuzzy preference programming to evaluate entrepreneurship orientation," Applied Soft Computing, vol. 13, no. 5, pp. 2749$2758,2013$.

[12] C. Hwang and K. Yoon, Multiple Attribute Decision Making Methods and Applications: A State-Of-The-Art Survey, pp. 1531, Springer, Berlin, Germany, 1981.

[13] İ Ertuğrul and N. Karakaşoğlu, "Performance evaluation of Turkish cement firms with fuzzy analytic hierarchy process and TOPSIS methods," Expert Systems with Applications, vol. 36, no. 1, pp. 702-715, 2009.

[14] Y.-M. Wang and T. M. S. Elhag, "Fuzzy TOPSIS method based on alpha level sets with an application to bridge risk assessment," Expert Systems with Applications, vol. 31, no. 2, pp. 309-319, 2006.

[15] X. L. Wang, Z. B. Qing, and Y. Zhang, "Decision making of selecting manufacturing partner based on the supply chain: study on TOPSIS method application," in Proceedings of the Cybernetics and Intelligent Systems, Singapore, December 2004.

[16] Y. Yang, X. Li, D. Chen, T. Yu, and W. Wang, "Application of GC-TOPSIS method in the process of supplier evaluation," in Proceedings of the International Conference on Management and Service Science, Wuhan, China, September 2009.

[17] A. Bilbao-Terol, M. Arenas-Parra, V. Cañal-Fernández, and J. Antomil-Ibias, "Using TOPSIS for assessing the sustainability of government bond funds," Omega, vol. 49, no. 12, pp. 1-17, 2014.

[18] M. Tavana, M. Keramatpour, F. J. Santos-Arteaga, and E. Ghorbaniane, "A fuzzy hybrid project portfolio selection method using data envelopment analysis, TOPSIS and integer programming," Expert Systems with Applications, vol. 42, no. 22, pp. 8432-8444, 2015.

[19] L. Y. Wu and Y. Z. Yang, "TOPSIS method for green vendor selection in coal industry group," in Proceedings of the International Conference on Machine Learning and Cybernetics, Kunming, China, July 2008.

[20] L. Zhao, X. Gao, and Y. Zhang, "Compare and contrast analysis to the development pattern of energy producing provinces with the aim of carbon emission reducing," in Proceedings of the International Conference on Management and Service Science, Wuhan, China, August 2010.

[21] E. Roszkowska and T. Wachowicz, "Application of fuzzy TOPSIS to scoring the negotiation offers in ill-structured negotiation problems," European Journal of Operational Research, vol. 242, no. 3, pp. 920-932, 2015.

[22] J. Seyedmohammadi, F. Sarmadian, A. A. Jafarzadeh, M. A. Ghorbani, and F. Shahbazi, "Application of SAW, TOPSIS and fuzzy TOPSIS models in cultivation priority planning for maize, rapeseed and soybean crops," Geoderma, vol. 310, pp. 178-190, 2017.

[23] C.-T. Chen, "Extensions of the TOPSIS for group decisionmaking under fuzzy environment," Fuzzy Sets and Systems, vol. 114, no. 1, pp. 1-9, 2000.

[24] R. K. Singh, A. Gunasekaran, and P. Kumar, "Third party logistics (3PL) selection for cold chain management: a fuzzy AHP and fuzzy TOPSIS approach," Annals of Operations Research, vol. 267, no. 1-2, pp. 1-23, 2018.

[25] X. Wang, C. Li, J. Shang, C. Yang, B. Zhang, and X. Ke, "Strategic choices of China's new energy vehicle industry: an 
analysis based on ANP and SWOT," Energies, vol. 10, no. 4, pp. 537-564, 2017.

[26] F. D. Tian, The Methodology of RSR and its Applications, China Statistics Press, Beijing, China, 1993.

[27] Z. Zhou, Z. Chen, and Y. Li, “The adoption behavior of new energy automotive technology in Chinese firms: a knowledge rigidity perspective," Journal of Renewable \& Sustainable Energy, vol. 4, no. 3, Article ID 031802, 2012. 


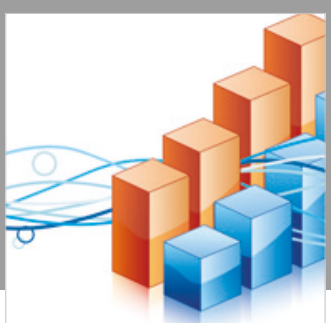

Advances in

Operations Research

\section{-n-m}
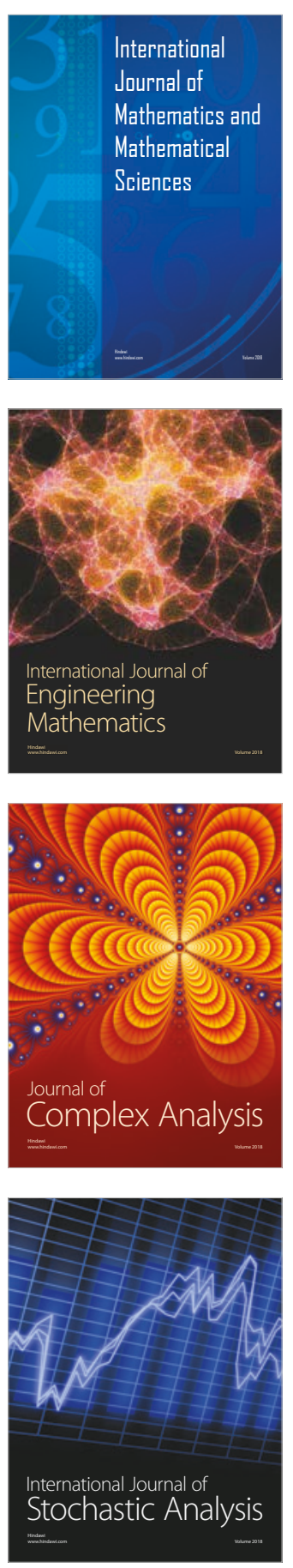
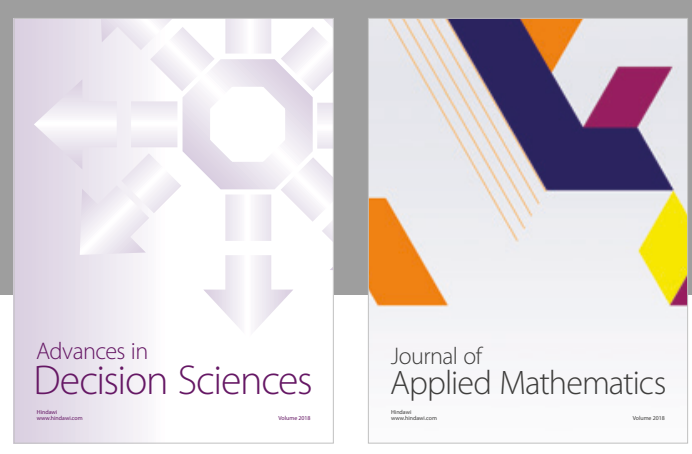

Journal of

Applied Mathematics
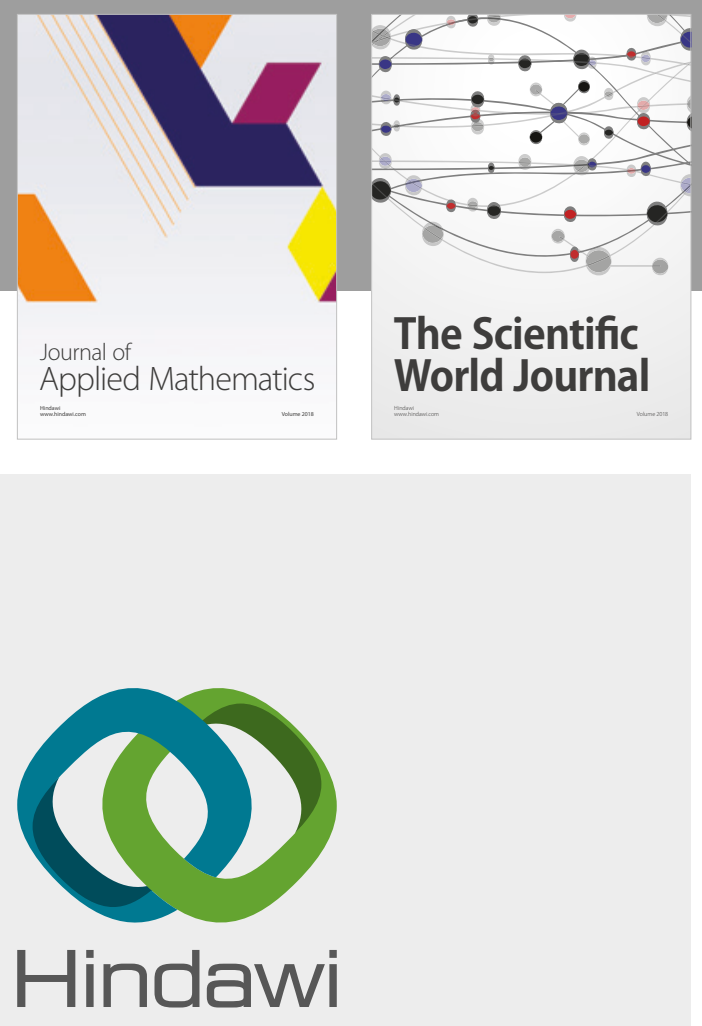

Submit your manuscripts at

www.hindawi.com

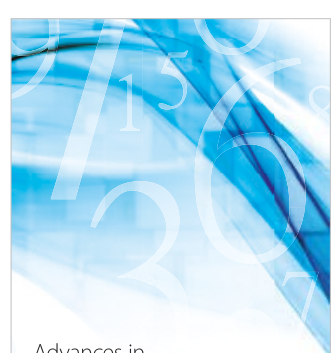

Advances in
Numerical Analysis
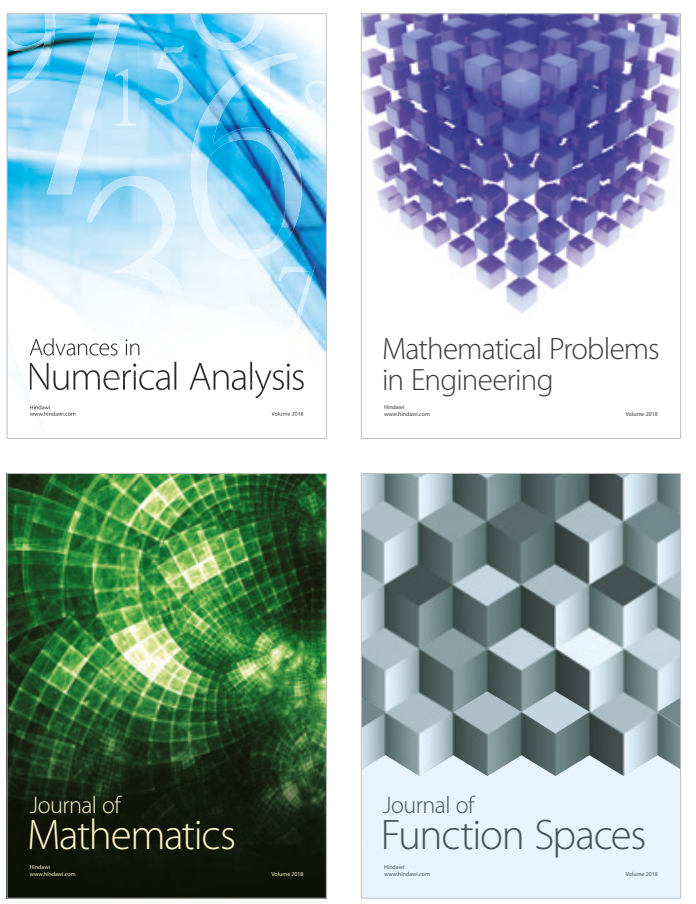

Mathematical Problems in Engineering

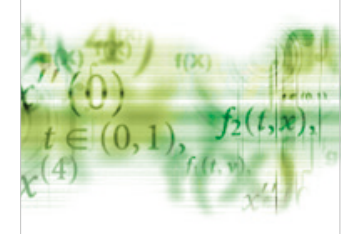

International Journal of

Differential Equations

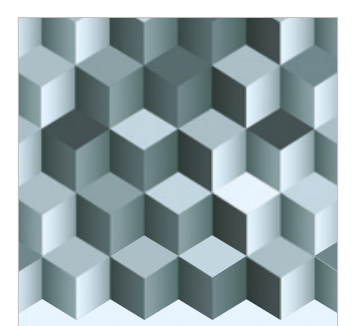

Journal of

Function Spaces

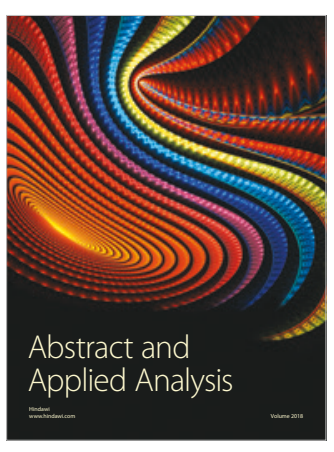

The Scientific

World Journal

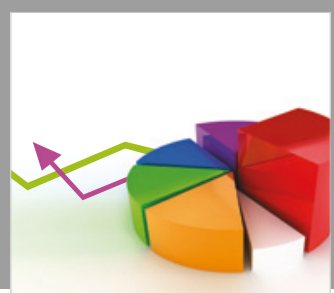

Journal of

Probability and Statistics
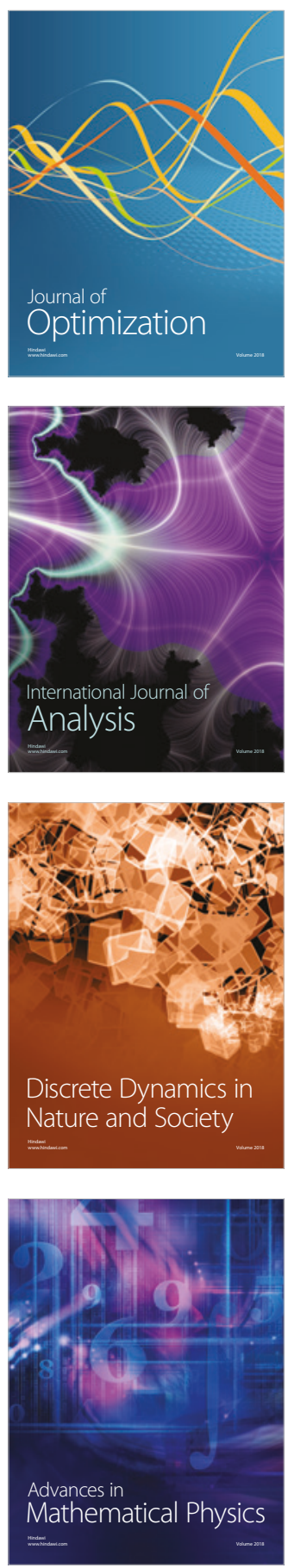